\title{
ВСЕМИРНАЯ ИСТОРИЯ
}

УДК $930.85+255$

DOI 10.23951/1609-624X-2017-9-9-14

\section{ЭЛЕВСИНСКИЕ МИСТЕРИИ КАК СПОСОБ ПРИЖИЗНЕННОГО ПЕРЕЖИВАНИЯ СМЕРТИ}

\section{О. А. Райкова}

Томский государственный педагогический университет, Томск

\begin{abstract}
Проблема смертности и переживания смерти является одной из самых актуальных для человека. Каждая культура предлагает свой вариант ее разрешения. В Древней Греции эпохи классики способом прижизненного переживания смерти выступали мистерии, среди которых наиболее массовыми являлись элевсинские таинства.

Элевсинские мистерии, возникшие на основе аграрного мифа о Деметре и Персефоне, позволяли людям пережить смерть, не умирая, еще при жизни и таким образом не только включить ее в круг бытия, но и получить надежду на лучшую посмертную участь. При этом мистерии в большей степени связаны с мифом, чем с собственно древнегреческой религией. Они выступали в качестве иллюстраций к мифу, ритуализируя его.

Проблема прижизненного переживания смерти при помощи элевсинских мистерий позволит лучше понять специфику древнегреческой культуры эпохи классики, а выводы можно использовать при подготовке курсов, посвященных истории и культуре Древней Греции.
\end{abstract}

Ключевые слова: Древняя Греция, элевсинские мистерии, таинства, миф.

Переживание смерти других и, как следствие, осознание собственной смертности, пожалуй, одни из самых сильных переживаний, с которыми сталкивается человек в своей жизни. Поэтому во все эпохи, от первобытности и до современности, культура вырабатывает механизмы, которые позволяют «амортизировать» опасный, чуждый жизни феномен - смерть.

В тех случаях, когда религия занимает значимое место в культуре, она берет функцию объяснения и переживания смерти на себя, как, например, в Древнем Египте, где жизнь воспринималась как подготовка к смерти, после которой, при проведении необходимых ритуалов, человека ожидала счастливая загробная жизнь [1, с. 83-84]. Если же религия не выполняет эту функцию, культуре приходится находить иные формы переживания смерти, что порой приводит к отрицанию смерти как естественного продолжения жизни и вытеснения ее за грань нормальной повседневности. Похожие процессы можно наблюдать и в современной культуре с ее культом молодости и негативным отношением к старости, за которой должна последовать смерть. В связи с этим рассмотрение альтернативных форм переживания смерти представляется актуальным, поскольку увеличивает число возможных вариантов ее «освоения» и принятия как естественного продолжения жизни. Одним из таких вариантов были элевсинские мистерии, возникшие в культуре Древней Греции и получившие распространение тогда, когда разум уже отказывался при- нимать посмертие, единое для всех, и не предполагающее лучшей участи или спасения.

Элевсинские мистерии вызывали интерес исследователей, обращавшихся к изучению истории и культуры Древней Греции. Так, их рассматривали в своих работах М. Нильсон [2], Д. Лауэнштайн [3], В. Ф. Отто [4], В. В. Латышев [5], Ф. Ф. Зелинский [6]. И все же многие вопросы, связанные с таинствами Элевсина, остаются: что происходило в ходе мистерий, какие факты относительно их можно считать достоверными и, наконец, в чем заключался истинный смысл таинств.

Возникновение как феномена мистерий в целом, так и элевсинских мистерий в частности связано со спецификой древнегреческой религии, которая представляла собой некое дополнение в виде обрядов к существующим мифологическим сюжетам и так и не превратилась в существенную культурную доминанту, которая бы определяла все сферы жизни древнегреческого общества. Кроме того, древнегреческая религия оказалась не в состоянии дать ответ на один из важнейших вопросов человеческого существования - об участи человека после смерти. В итоге эту функцию и взяли на себя мистерии - «таинства» (именно этим словом описывает элевсинские мистерии большинство исследователей) - нечто неизвестное, скрытое от глаз и слуха непосвященных, некое действо, цель которого приобщение его участников к тайному знанию.

Переход от жизни к смерти - это существеннейшее экзистенциальное переживание человека 
античности, поскольку он давался ему чрезвычайно тяжело, так как греческая религия не давала четких представлений о смерти и загробном существовании. Формой осознания смерти выступал миф, содержащий «поэтические» метафоры, связанные со смертью, например, о путешествии Орфея в Аид.

В религии греков не было мистики спасения был лишь порыв осмыслить, освоить, как бы «приручить» смерть. «Жизнь» после смерти для греков не была так актуальна - их религия мало что говорила о ней. Так, Ф. Ф. Зелинский указывает на то, что целью существования мистериальных культов Деметры и Диониса было «утешение в смерти» [6, с. 114], поскольку древнегреческая религия в целом не была направлена на мистику посмертного существования человека, оставаясь «религией живых». Первоначально нет никаких исключений из этого правила, жизнь после смерти одинаково пугающа и безнадежна для всех. Свидетельством этого служит момент из «Одиссеи» Гомера, когда Одиссей встречает в царстве теней Ахиллеса. Одиссей пытается утешить его былыми заслугами и почестями, доставшимися Ахиллесу при жизни, однако герой дает ему неутешительный ответ:

«О Одиссей, утешения в смерти мне дать не надейся;

Лучше б хотел я живой, как поденщик, работая в поле,

Службой у бедного пахаря хлеб добывать свой насущный,

Нежели здесь над бездушными мертвыми царствовать, мертвый» [7, с. 146].

Таким образом, загробный мир древних греков не предполагал дифференциации посмертия в зависимости от личных заслуг.

Человек классической эпохи уже не мог смириться с таким положением вещей, поскольку в это время из общества выделяется личность, стремящаяся к достижению индивидуальных благ, в том числе лучшего из возможных вариантов посмертного существования. Активный поиск мыслящего, рефлексирующего сознания заставляет человека классической эпохи обратить внимание на аграрный по своей природе культ Деметры, возникший на основе мифа о похищении дочери богини, Персефоны, Аидом - владыкой подземного мира, пребывании ее в загробном мире в течение определенного времени; страданиях матери, ищущей дочь, и, наконец, счастливом воссоединении матери и дочери [8], что, в свою очередь, находит отражение в природных циклах временного угасания и последующего возобновления плодоносящей способности земли.

Образ богини Деметры изначально вызывал споры в среде исследователей, поскольку в ходе изучения этимологии имени этой богини вторую часть переводили довольно определенно как «мать», тогда как первую переводили по-разному: «земля» или «зерно» [2, с. 33]. В связи с этим потребовалось некоторое время для определения сущности Деметры - как Матери-Земли или Матери зерна (то есть богини злаковых культур и земледелия). Однако Дж. Дж. Фрэзер, обратившись к V гомерову гимну, обращает внимание на то, что Земля в нем выступает в качестве самостоятельного действующего лица, помогая Аиду заполучить Персефону; поэтому Деметру более вероятно считать Матерью зерна. Персефону же, в свою очередь, - зерном, брошенным в землю, где оно пребывает до времени всходов [9, с. 371].

Возможно, именно земледельческий характер культа Деметры способствовал тому, что постепенно в сознании древних греков он соединился с ключевой антиномией человеческого бытия: жизнь смерть. Можно предположить, что этому в значительной степени способствовал погребальный обряд древних греков: «у греков были приняты две формы погребального обряда: закапывание тела в землю или сожжение его на костре, после чего прах укладывали в урну, которую либо закапывали, либо помещали в гробницу» [10, с. 311]. Быть может, кремация наводила греков на мысль о том, что, подобно жертвенным животным, сжигаемым на алтарях и возносящихся к трону богов для их насыщения, душа человека вместе с дымом также поднимается в небо и пребывает в каком-то специальном месте; при погребении же в земле невольно возникала параллель между зерном, пребывающим во мраке до момента прорастания, и умершими [6, с. 113-114]. В результате сформировались представления о том, что Деметра и Персефона являются богинями, отвечающими за существование человека, но если Деметра вела человека в его земной жизни, то Персефона, как жена хозяина подземного мира Аида, отвечала за его существование за гробом [4, с. 260-261]. Именно поэтому такое большое значение приобретают ритуалы, проводимые в честь двух богинь в Элевсине.

Таким образом, мистериальный миф с участием Деметры и Персефоны из типичного аграрно-календарного мифа, повествующего о природных циклах смены времен года, а также сельскохозяйственном обороте злаковых культур, преобразовался в миф о человеческой жизни и смерти.

V гомеров гимн, в котором впервые упоминаются элевсинские мистерии, исследователи относят к VII-VI вв. до н. э. [5, с. 199]. Как видно из текста гимна, в то время ритуалы в Элевсине уже имели важное значение для людей, поскольку прошедший их мог надеяться на лучшую долю в загробном мире, а поскольку установила их сама Деметра, рассказывать о таинствах запрещалось: 
Жертвенный чин показала священный и всех посвятила

В таинства. Святы они и велики. Об них ни расспросов

Делать не должен никто, ни ответа давать на расспросы:

В благоговенье великом к бессмертным уста замолкают.

Счастливы те из людей земнородных, кто таинство видел.

Тот же, кто им непричастен, по смерти не будет вовеки

Доли подобной иметь в многосумрачном царстве подземном [8, с. 104].

Этот фрагмент свидетельствует о том, что один из основных смыслов участия в мистериях - обретение лучшей посмертной участи через сильное эмоциональное переживание. Мистерия выступает как форма приобщения к смерти, переживание ее, пропускание ее через себя, в результате которой преодолевается страх смерти, так как смерть принимается сознанием человека, становится частью его жизни; таинство позволяет человеку прикоснуться к одной из самых сокровенных тайн бытия - смерти, находясь еще «по эту сторону» - будучи живым. Тем самым опасный хаос и исчезновение становятся частью космоса, частью бытия. При этом мистерия тесно связана с мифом - практически полностью основывается на нем и выступает в качестве иллюстрирующих его ритуалов.

Как отмечал Ф. Ф. Зелинский, первоначально элевсинские таинства были местным культом, затем были приняты в число афинских культов, а ближе к классической эпохе элевсинский культ Деметры приобрел общегреческое значение [6, c. 115], и люди со всей Греции стали посещать это святилище с целью приобщения к таинствам.

Максимально простые изначально, со временем мистериальные действа все более и более усложнялись, будучи на высших ступенях доступными лишь для посвященных. В ходе мистерий предполагалось прохождение нескольких уровней посвящения, поэтому мистерии подразделялись на несколько последовательно проходимых ступеней, вплоть до великих мистерий. В. В. Латышев отмечает, что «в посвящении различались три степени... первой было посвящение в малые мистерии. Никто не мог быть посвящен в великие мистерии без предварительного посвящения в малые... При посвящении в великие таинства различались 2 степени... между которыми был промежуток не менее года; достигшие высшей степени посвящения назывались... созерцателями» [5, с. 202-203].

Исследователям не удалось восстановить весь процесс посвящения, поскольку мистериальные практики Элевсина были крайне закрытыми и раз- глашение сведений о том, что происходит при посвящении, сурово наказывалось, вплоть до смертной казни. Поэтому общеизвестная формула, которая известна нам от Климента Александрийского: «я постился, я пил кикеон, я взял из сундука, и поработав, я положил в корзину, а из корзины в сундук» (цит. по [2, с. 62]) вызывает вопросы у исследователей вплоть до настоящего времени. Дело в том, что любой элемент из этой формулы может повлиять на видение мистерий в целом и на понимание характера происходящего в ходе их действа. Если предположить, что правдивыми являются два первых элемента, то в этом случае мистерии носили достаточно «сдержанный» характер, не предполагавший излишних проявлений эротического начала. Если же и третий элемент формулы достоверен, то речь идет о дополнении мистериального земледельческого культа мотивами зарождения жизни, перерождения и, как следствие, эротизацией разыгрываемых перед мистами драматических представлений.

Так, М. Нильссон по поводу этой формулы отмечает, что «первые два обряда - поститься и пить кикеон - известны как практиковавшиеся на Элевсине. Но об остальных этого нельзя сказать, да и вообще, неизвестно, относятся ли они к Элевсину. Возможно, они позаимствованы из мистерий Деметры в Александрии» [2]. То есть, по мнению М. Нильссона, вполне вероятно, что Климент Александрийский описывает несколько измененные под влиянием эпохи эллинизма таинства, куда вполне мог проникнуть эротический элемент, пришедший из восточной культуры. В то же время Д. Лауэнштайн подробно описывает процесс манипуляций с корзинами и материнским лоном (перекладывание его из одной корзины в другую и возврат в первую корзину), осуществляемый мистами [3, с. 196]. По мнению Д. Лауэнштайна, «обряд содержит образ того, что должно произойти в душе миста, в котором элевсинское таинство таким способом вызывает желанное пробуждение, открывает способность к духовидению, - образ оплодотворения свыше» [3, с. 196]. Однако В. Ф. Отто указывает, что кульминацией мистерий была демонстрация пшеничного колоса, поскольку это «...полностью соответствует неотделимому от элевсинских мистерий мифу о возникновении земледелия. Пшеничный колос был даром Деметры» [4, с. 265]. Следует отметить, что в пользу мнения В. Ф. Отто свидетельствует тот факт, что кикеон, который пили мисты, не был алкогольным или дурманящим напитком:

...Попросила, чтоб дали воды ей,

Ячной мукой для питья замесивши и нежным полеем.

Та, приготовивши смесь, подала, как велела богиня. 
Выпила чашу Део. С этих пор стал напиток обрядным [8, с. 95].

То есть мисты, постившиеся, а затем выпивающие кикеон, вряд ли входили бы в состояние, при котором представления эротического характера произвели бы на них сильное впечатление.

Таким образом, если в элевсинских мистериях и присутствовали сцены или предметы эротического характера, то «...они имели лишь то значение, которое было у них в древности. Это были амулеты плодородия» [2, с. 62], т. е. они были лишь указанием на первоначально аграрный характер культа, где увеличение плодородия земли играло ключевую роль. Но поскольку со временем смысл элевсинских мистерий стал иным, относящимся к иному миру и загробному существованию, эротические элементы культа остались лишь в виде рудиментов.

Следует отметить, что если до классической эпохи элевсинские таинства не были столь известны, то в эпоху классики многие греки стремятся приобщиться к ним. Можно сказать, что участие в мистериях стало массовым явлением. Пример массовости посвящений в мистерии и, как следствие, осознание их важности и необходимости приводит В.В.Латышев: «...многие афинские граждане посвящались еще в детском возрасте благочестивыми родителями; такое посвящение обозначалось специальным термином - посвящение от очага...» [5, c. 203].

Элевсинские таинства были не единственными в культуре Древней Греции, хотя, вероятно, самыми древними. Кроме элевсинских, существовали дионисийские мистерии, из которых впоследствии возник древнегреческий театр, а также более «рациональные» орфические таинства, превратившие необузданные празднества в честь Диониса в религиозно-философское учение [6, с. 114-117]. Все эти таинства отвечали на вопрос о посмертном существовании по-своему, акцентируя внимание на наиболее значимых для каждого культа аспектах.

Популярность элевсинских мистерий по сравнению с остальными объясняется, скорее всего, тем, что их отличительной чертой был «всеобъемлющий» характер: прикоснуться к таинствам Деметры разрешалось всем грекам без исключения, даже рабам, и, в качестве исключения, даже иностранцам: «посвящение в элевсинские мистерии было доступно для всех эллинов. < .. > Варвары не допускались к посвящению, хотя и тут встречаются исключения в пользу отдельных, особенно выдающихся, лиц. Доступ к участию в мистериях не был закрыт даже рабам, если они были не варварского происхождения» [5, с. 202]. Такая «демократичность» элевсинских таинств, по мнению Ф. Ф. Зелинского, связана со спецификой силы, с которой соприкасается в ходе мистерий человек - со смертью, единым завершением жизни для всех людей $[6$, с. 116], однако и дионисийские, и орфические таинства также позволяли человеку прикоснуться к смерти как форме инобытия. Вероятнее всего, дело в том, что обрядовая сторона элевсинских мистерий была понятна и близка многим, в то время как, например, философские представления орфиков были доступны не всем.

При обращении к элевсинским таинствам ключевым остается вопрос о том, что являлось их кульминацией, и, как следствие, вопрос о переживаниях, испытываемых мистами по ходу действа. Исследователи сходятся во мнении по поводу заключительной части посвящения: считается, что апогеем действа была демонстрация собравшимся сжатого колоса как символа вечной жизни [2, с. 76$]$. Именно в этот момент мисты должны были понять, что смерть - это естественная часть круговорота жизни, поскольку зерно, бывшее в земле, прорастает, дает урожай, и цикл этот длится вечно.

М. Нильссон, описывая чувства, которые, возможно, испытывали мисты в ходе мистерий, отмечает, что «суть мифа в воссоединении Матери и Девы. <..> Древний аграрный миф поднялся в сферу человеческих взаимоотношений. Горе и печаль обездоленной матери, ее отчаянные поиски затрагивают глубочайшие человеческие чувства. $<\ldots>$ В противовес этой горькой печали, воссоединение матери с дочерью вызывает бурную радость, ликование. Сердца мистов наполнялись сильными эмоциями. Мистерии не носили мрачного оттенка; они дарили людям радость и веселье. Их основной темой было не похищение и разъединение, а воссоединение» [2, с. 74]. Из этого описания видно, что аграрный миф в элевсинских мистериях превращается в миф о человеке, полном чувств и эмоций, поэтому переживания богини-матери столь остро переживаются мистами. Они проходят весь путь вместе с богинями элевсина, незримо присутствуя в мифе и сопереживая богиням. В результате они переживают глубочайшее мистериальное потрясение, подобное катарсису, обладающее, однако, собственными отличительными чертами: драматизм разыгрываемого действа, который усиливает воздействие на участников таинства, достигается за счет максимальной детализации мифологического повествования, положенного в основу мистерий; каждая ступень посвящения сопровождается многочисленными ритуалами, которые опираются на историю, рассказанную в мифе, и постоянно апеллируют к нему; и, наконец, хотя мисты испытывают столь же сильные, как и при катарсисе, переживания, основа их иная - не страх, а радость и ликование от понимания того, что для них открыт лучший вариант посмертного существования из возможных. 
Таким образом, элевсинские мистерии возникают на основании аграрного мифа о Деметре и Персефоне, но постепенно суть их меняется, поскольку происходит переосмысление мифологического повествования, которое превращается в миф о человеческой жизни и смерти. Благодаря вовлеченности и переживанию сильных положительных эмоций элевсинские таинства дают мистам возможность при жизни «пережить» смерть, принять ее и получить надежду на лучшую посмертную участь и благодаря своей общедоступности и массовости дают ответ на вызов, возникший в древнегреческой культуре эпохи классики.

При этом мистерии оказываются в большей степени связаны с мифом, чем с собственно древ- негреческой религией, они выступают в качестве иллюстраций к мифу, ритуализируя его, поскольку действа, в которых принимали участие мисты, в большей степени представляли собой разного рода ритуалы, позволяющие участникам таинств погрузиться в разыгрываемое для них повествование.

Проблема механизма прижизненного переживания смерти при помощи Элевсинских мистерий, рассматриваемая в данном исследовании, позволит лучше понять специфику древнегреческой культуры эпохи классики, а выводы, полученные автором, могут быть использованы при подготовке курсов, посвященных истории и культуре Древней Греции.

\section{Список литературы}

1. Райкова О. А. Древнегреческий миф классической эпохи: социокультурное обоснование, сферы проявления и аспекты трансформации: дис. ... канд. филос. наук. Томск, 2012. 129 с.

2. Нильссон М. Греческая народная религия / пер. с англ. С. Клементьевой. СПб.: Алетейя, 1998. 218 с.

3. Лауэнштайн Д. Элевсинские мистерии / пер. с нем. Н. Федоровой. М.: Энигма, 1996. 368 с.

4. Отто В. Ф. Смысл Элевсинских мистерий: пер. с англ. // Кереньи К. Элевсин: архетипический образ матери и дочери. М.: Рефрл-бук, 2000. C. $251-274$.

5. Латышев В. В. Очерк греческих древностей. Богослужебные и сценические древности. СПб.: Алетейя, 1997. 320 с.

6. Зелинский Ф. Ф. История античной культуры. 2-е изд. СПб.: Марс, 1995. 380 с.

7. Гомер. Одиссея / пер. с древнегреч. В. Жуковского. М.: Правда, 1984. 320 с.

8. Гомеров гимн. К Деметре // Эллинские поэты. М.: Художественная литература, 1963. С. 88-104.

9. Фрэзер Д. Д. Золотая ветвь: исследование магии и религии. М.: Политиздат, 1983. 703 с.

10. Винничук Л. Люди, нравы и обычаи Древней Греции и Рима / пер. с польск. В. К. Ронина. М.: Высш. шк., 1988. 496 с.

Райкова Ольга Анатольевна, кандидат философских наук, доцент, Томский государственный педагогический университет (ул. Киевская, 60, Томск, Россия, 634061). E-mail: didenko.oa@list.ru

Материал поступил в редакциию 30.05.2017.

DOI 10.23951/1609-624X-2017-9-9-14

\section{ELEUSINIAN MYSTERIES AS A WAY OF LIFETIME EXPERIENCE OF DEATH}

\section{O. A. Raykova}

\section{Tomsk State Pedagogical University, Tomsk, Russian Federation}

The problem of mortality and the experience of death is one of the most urgent for a person. Each culture offers its own solution. In the Ancient Greece of the era of the classics, mysteries were the means of the lifetime experience of death, among which the most widespread were the Eleusinian sacraments.

The emergence of the mystery phenomenon is connected with the specificity of the ancient Greek religion, which was a kind of complement in the form of rituals to existing mythological subjects and never turned into an essential cultural dominant that would determine all spheres of life of ancient Greek society.

The Eleusinian Mysteries, which arose on the basis of the agrarian myth of Demeter and Persephone, allowed people to survive death without dying, while still alive, and thus not only include it in the circle of being, but also get hope for a better posthumous fate. In this case, the mysteries are more connected with the myth than with the actual Greek religion. They acted as illustrations to the myth, ritualizing it.

The problem of the lifetime experience of death with the help of the Eleusinian Mysteries will allow us to understand better the specifics of the ancient Greek culture of the classical epoch, and the findings can be used in the preparation of courses on the history and culture of ancient Greece.

Key words: Ancient Greece, Eleusinian Mysteries, sacraments, myth. 


\section{References}

1. Raykova O. A. Drevnegrecheskiy mif klassicheskoy epokhi: sotsiokul'turnoye obosnovaniye, sfery proyavleniya $i$ aspekty transformatsii. Dis. kand. filos. nauk [Ancient Greek myth of the classical era: sociocultural justification, spheres of manifestation and aspects of transformation. Diss. cand. philos. sci.]. Tomsk, 2012. 129 p. (in Russian).

2. Nil'sson M. Grecheskaya narodnaya religiya [Greek popular religion]. translation from English by S. Klementyeva. St. Petersburg, Aleteya Publ., 1998. 218 p. (in Russian).

3. Lauenshtayn D. Elevsinskiye misterii [Eleusinian Mysteries]. Translation from German by N. Fedorova. Moscow, Enigma Publ., 1996.368 p. (in Russian).

4. Otto V. F. Smysl Elevsinskikh misteriy [The meaning of the Eleusinian Mysteries: translation from English]. Keren'i K. Elevsin: Arkhetipicheskiy obraz materi i docheri [Eleusis: Archetypal image of mother and daughter]. Moscow, Refl-buk Publ., 2000. Pp. 251-274 (in Russian).

5. Latyshev V. V. Ocherk grecheskikh drevnostey. Bogosluzhebnyye i stsenicheskiye drevnosti [Essay on Greek antiquities. Liturgical and scenic antiquities]. St. Petersburg, Aleteya Publ., 1997. 320 p. (in Russian).

6. Zelinskiy F. F. Istoriya antichnoy kul'tury [History of ancient culture]. 2nd edition. St. Petersburg, Mars Publ., 1995. 380 p. (in Russian).

7. Gomer. Odisseya [Odyssey]. Translation from Ancient Greek by V. Zhukovskiy. Moscow, Pravda Publ., 1984. 320 p. (in Russian).

8. Gomerov gimn. K Demetre [Homeric Hymn to Demeter]. Ellininskiye poety [Hellenic poets]. Moscow, Khudozhestvennaya literatura Publ., 1963. Pp. 88-104 (in Russian).

9. Frezer D. D. Zolotaya vetv': issledovaniye magii i religii [The Golden bough: a study in magic and religion]. Moscow, Politizdat Publ., 1983. 703 p. (in Russian).

10. Vinnichuk L. Lyudi, nravy i obychai Drevney Gretsii i Rima [People, manners and customs of ancient Greece and Rome]. Translation from Polish by V. K. Ronin. Moscow, Vysshaya shkola Publ., 1988. 496 p. (in Russian).

Raykova O. A., Tomsk State Pedagogical University (ul. Kievskaya, 60, Tomsk, Russian Federation, 634061).

E-mail: didenko.oa@list.ru 